\title{
Impacts of the Response-to-Intervention Approach on German Elementary Students
}

\author{
Stefan Voß, Yvonne Blumenthal \\ University of Rostock, Germany
}

\begin{abstract}
Since the ratification of the Convention on the Rights of Persons with Disabilities Germany has been forced to restructure the school system towards an inclusive education. This is a challenge for Germany as there is a high rate of students with special educational needs and a highly selective school system. In the following report, the Rügen Inclusion Model (RIM) will be described as an alternative inclusive schooling concept. RIM is conceptually based on the US Response-toIntervention (RTI) approach. Being the first largescale implementation of RTI structures in Germany, the study will focus on how RTI can be successfully implemented and if it is viable for successful prevention of special educational needs and an appropriate inclusive schooling model. Starting from a brief introduction to RTI, the RIM concept is outlined by taking into account individual core elements. Subsequently, we give an overview of the results of the comprehensive evaluation study. Within a control group study (treatment group $N=441$, control group $N=385$ ) the effectiveness of RIM was compared with traditional schooling structures. Systemic variables and students-related data were evaluated at the end of elementary school. All in all, the RTI approach seems to be a promising framework model for an inclusive school system in Germany.
\end{abstract}

\section{Introduction}

Independent from the legal determination (United Nations Convention on the Rights of Persons with Disabilities), most of the research results promote inclusive concepts for schools [e.g. 1, 2]. However, there are ambiguous findings. On the one hand, results show that if school students with special educational needs (SEN) are taught in an inclusive environment, their academic performance is mostly affected in a positive way. On the other hand, their social status and self-concept is more often disadvantageous as opposed to students that are being taught in separative school systems. Thus, the socio-emotional development of students with SEN can be regarded as a problem area in the context of inclusive education [e.g. 3].

Recent research has indicated that school students with poor learning outcomes are especially at risk of social rejection [e.g. 4, 5]. Even though those findings may cause some concern, they do not express an attitude against inclusion. Instead they invite to answer the question how the socioemotional situation of students with SEN in inclusive settings can be improved?

In the discourse about inclusive approaches at schools, the US-American Response-to-Intervention approach (RTI) [e.g. 6] is highly discussed in Germany [e.g. 7, 8], but also critically evaluated [e.g. 9]. First comprehensive implementing experiences show that RTI is indeed a successful schooling approach for teaching students with difficulties in learning, language and behavior in a joint setting [e.g. 10]. In the following chapters, we introduce the study that we conducted to examine if an inclusive schooling approach according to RTI is also benefiting for the development of students, especially those with SEN. First, we will give an overview of the concept of RTI and then describe its specific implementation in the Rügen Inclusion Model (RIM).

\section{The concept of RTI}

The term RTI describes a schooling concept which aims at preventing and, if needed, integrating learning and behavior disabilities and provides an alternative way for identifying learning and development difficulties $[6,11,12]$. Consequently, it is of utmost importance to design and structure school lessons in such ways that it serves and supports every student in its development. If students' response positively to the educational interventions, they can be seen as successful for their individual learning progress. Since the remittal of the Individuals with Disabilities Education Improvement Act in 2004, the RTI approach has gained high significance in the USA and has been implemented in half of the states already [13].

In fact, there is no specific RTI approach as such [13]. Instead, it should be regarded as a conceptual scaffold in which different core elements are connected with each other to build multiple structures. These core elements comprise [12]:

- a multi-level prevention system

- progress monitoring and the documentation of development as well as 
- research-based instruction and evidence-based intervention.

\subsection{Multi-level prevention system}

The RTI approach can be illustrated as a multitiered supporting system in which (special) educational interventions for primary, secondary or tertiary prevention of educational and developmental difficulties [14] are realized [12]. Depending on the extend and severity of the students' learning and development problems, the educational work on each tier differs in a) the intensity and specificity of the interventions, b) the individual realization of the interventions and c) the diagnostic methods (see Figure 1) [15]. Across the different prevention levels, interventions can be intensified by an increasing frequency and extension of supporting measures. These additional measures ae provided for small learning groups by qualified educators [16]. There is no specification on how many tiers the system should comprise, so that the approach sometimes includes two or four levels [6] but mostly three levels can be found [16].

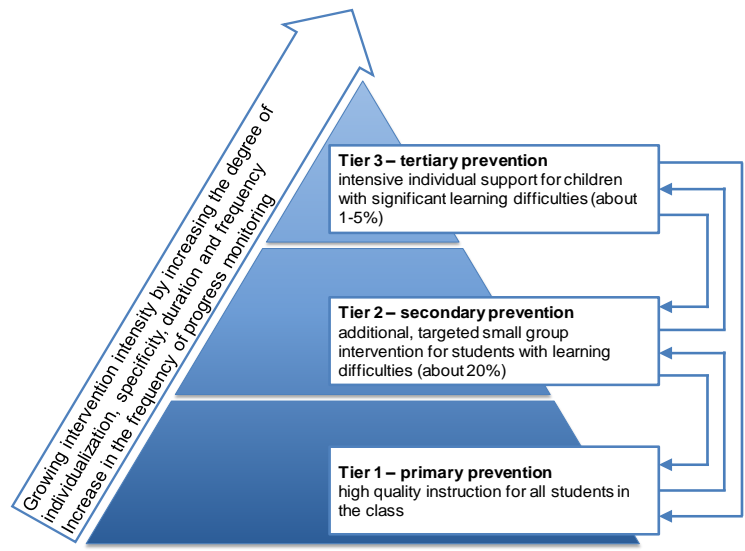

Figure 1: Illustration of a RTI model comprising 3 tiers [11, p. 71]

A distinct advantage of RTI is that usual 'wait-tofail' structures can be avoided. Instead, educational support is supplied right from the beginning. Moreover, it provides a suitable alternative to rigid processes by an individual and flexible support that meets the individual needs of each student $[6,11]$.

\subsection{Progress monitoring for a data-based decision making}

RTI is based on the formative evaluation of instruction and interventions with the help of objective, reliable and valid data of all students [12]. Every school year, two or three universal screenings are conducted in order to identify students at risk of developing learning difficulties. Furthermore, the learning progress is monitored continuously on a monthly or weekly basis so that the effectiveness of the applied measures can be assessed [12]. Curriculum-based measurements (CBM) are used for the progress monitoring [e.g. 17, 18, 19]. In order to receive differentiated performance profiles, the students' academic strengths and weaknesses are determined so that educational support can be initiated for identified students at risk. Depending on a student's progress, the RTI approach allows a dynamic exchange between the different prevention levels. Two different procedures can be applied for this process: the standard-protocol approach or problem-solving approach [6].

The standard protocol approach determines fixed diagnostic criteria (e.g. school performance below a percentile rank of 26) that help to assign students to an adequate prevention level where they receive suitable educational support. Certain interventions are provided for all students who show similar learning problems [6]. The problem-solving approach intends for teachers, principals and, where required, also parents and further experts (for instance school psychologists) to meet in conferences and decide on suitable supporting measures based on gathered data of the students' performance and development. Then, each student receives an individualized education plan which includes information about specific learning goals and actions to take into account. Furthermore, they determine for how long measures have to be applied and how to verify the accomplishment of set goals [6]. Recently there have been reports about combining elements of both approaches [13].

\subsection{Research-based instruction and evidence-based intervention}

In the USA the No Child Left Behind Act of 2001 promotes the use of effective educational practices, which are justified by scientifically based research. According to the tier this means a highquality core instruction (tier 1) that meets the needs of most students. For students at risk (tier 2 or 3 ) evidence-based interventions are recommended. An intervention is evidence-based if "data from scientific, rigorous research designs have demonstrated (or empirically validated) the efficacy of the intervention" $[12$, p. 6].

This practice provides a foundation for high-quality education of all students and optimal support for students with learning disabilities. The U.S. Department of Education has established the What Works Clearinghouse to provide teachers and others with a reliable and proven source of scientific evidence regarding effective and scientifically supported educational methods. 


\section{Implementation of the core elements in RIM}

Principal challenges for implementing the RTI approach in Germany are the traditionally highly selective school structures that do only partly allow a systematic co-operation between mainstream and special education. Furthermore, there are only a few specific procedures for progress monitoring and teacher training courses available in Germanspeaking countries, which do also fulfill the criterion to be evidence-based or research-based. However, there are reports in respective literature about evidence-based components of an effective prevention and support e.g. for students with reading and writing difficulties [20]. Based on this analysis and other findings on effective teaching methods for students with learning disabilities [21], training courses were chosen.

If students do not respond adequately to measures of internal differentiation on tier 1 , they may not accomplish performance standards of their grade. In this case further and more intense educational support needs to be provided on tier 2 . The class or subject teacher instructs those students at need individually in their regular lessons as well as in additional small learning groups of three to five students. Thus, they receive their educational support either parallel to their lessons or additionally to them. If students still do not respond to these measures on tier 1 and 2 they may develop severe learning disabilities and therefore need additional support on tier 2. This support is provided by a special education teacher in individual sessions or in small learning groups of three students maximum.

Whereas five additional lessons per week are provided on the second prevention level within the first school year, they are reduced to three additional lessons per week in the second school year. If students do not respond to the educational measures on all three tiers, they receive an individual differentiated education plan. For particular students it may even be reasonable to repeat one grade. In this case it is important that they get specific support to gain basic competences so that they will be able to fulfill minimum standards for a successful learning progress.

In order to systematically monitor whether all students benefit from instruction, screenings are conducted every half a year and CBM are conducted additionally once a month in mathematics, reading and writing. Students with learning difficulties need to participate in further weekly CBM and qualitative diagnostic procedures that investigate suitable supporting measures.

All involved teachers and educators meet regularly in co-operative case consultations to decide on the specific content and implementation of additional educational support. The RIM combines the problem-solving with the standard-treatmentprotocol approach in a constructive way. Acquired data of the students are evaluated based on interpretation routines. However, if necessary, individual case decisions are made. Further experts, such as psychologists, speech therapists and the principal as well as parents can also participate in the case consultations so that all possible supporting resources can be activated.

To strengthen the students' emotional and social skills, a universal training program to promote the social skills of the whole class will be implemented. Furthermore, an effective classroom management should prevent problematic behavior. Special proactive measures are the "Good Behavior Game" $[22,23,24]$.

Students who a) nonetheless show conspicuous behavior or b) do not develop as desired despite these measures or c) already have pronounced disorders receive additional selective measures within tier 2. These are based on manualized planning and action aids as a proposal for individual support [25]. The progress monitoring of the developmental process of the students takes place mainly through standardized behavioral observations at the individual or class level and through multiinformal questionnaires. Non-responders to tier 2 or students with pronounced disorder also receive indexed help on tier 3. These consist from specific interventions as well as programs for networking between school and extracurricular help (e.g. child and adolescent psychiatry or social workers).

\section{Summarized overview of the evaluation study}

RIM is the first large-scale approach to implement RTI structures in Germany. Two main aspects were in the focus of research:

- How can core elements of RTI be successfully implemented, especially in the context of (a) traditionally established selective schooling structures, (b) having only a few measures available for progress monitoring, and (c) drawing on limited findings on the evidence of teaching materials?

- Is the RIM concept viable for a successful prevention of special educational needs and for a suitable inclusive schooling?

\subsection{Research questions}

The following questions were tried to be answered based on the acquired data and their evaluation:

- To which extend is a performance progress of students with individual cognitive preconditions noticeable in the treatment and control group 
and does the framework succeed to develop a performance-oriented elementary school despite using an inclusive schooling approach?

- Which school setting is more benefiting for the development of students at risk of poor learning outcomes?

- Which school setting is more benefiting for the students' socio-emotional development and situation?

- Which school setting is more benefiting for the language, school performance and socioemotional development particularly of students with language and speech disabilities?

- Do the different elementary school concepts of the treatment and control group lead to a different frequency and quality of additional educational support?

- Which effects regarding the emotional-social situation of the students can be achieved?

- To which extend do participating teachers accept new schooling approaches? Do teachers implement the core elements of the approach similarly?

- To which extend are parents satisfied with the educational work according to the RIM?

\subsection{Overview of the study design}

The effectiveness of RIM was examined in a control group study from 2010 to 2014. The following illustration of the comprehensive evaluation study for RIM needs to be considered as a summary of fundamental procedures and their results due to the multitude of necessary partial studies and results. A detailed description of the applied methods and findings is given in Voß et al. [26] or Blumenthal and Voß [27] in German language.

Data about school performance and development progress were acquired for students who started going to school in 2010 at public elementary schools on the Isle of Rügen (treatment group, $\mathrm{N}=441$ ). A control group was chosen with students who were also enrolled to school in 2010 at public elementary schools but also at elementary schools with specific diagnostic intervention classes (DIC) ${ }^{1}$ or elementary schools for students with language disorders in the City of Stralsund (a city situated in the same region, $\mathrm{N}=385$ ).

Different variables from the students (academic performance, language and socio-emotional development) as well as from the teachers (implementation of and attitude towards the RIM

\footnotetext{
${ }^{1}$ Diagnostic intervention classes were created at regular schools for students with learning and behavioral problems. They offer special conditions: an extended learning time (curricula for two years are stretched over a period of three years), a limited number of students in a classroom (12-15 students) and additional lessons with special education teachers to optimize students' individual achievements.
}

concept) and the parents (satisfaction with the schooling concept, socio-economic situation) were chosen as indicators to assess the effectiveness of RIM. Furthermore, systemic markers were gathered. At the end of each school year, students had to complete established German school performance tests in reading, writing and mathematics according to the respective curricular standard in order to assess their academic performance level. Results of Germany-wide standard-based tests (VERA) that are conducted at the end of third grade were also included. Moreover, standardized student, peer and teacher questionnaires were used to assess the socioemotional situation of the students. They also involved established international measurements, such as the SDQ [28] and the socio-metric questionnaire according to Coie and Dodge [29].

As it is quite important that everyone involved in this study is open-minded towards comprehensive school reforms, we examined the attitude of all educators towards the overall RIM concept as well as particular conceptual elements and inclusion in general. Furthermore, we interviewed parents of students in both groups about their satisfaction with the educational work at the schools. The teacher and parent interviews were carried out with selfdeveloped questionnaires.

Further comparison criteria for both school systems were the frequency and particular manifestations of additional or special educational needs after four years at school.

In order to receive a differentiated view on the development of students with different learning and development preconditions, further analyses of various subgroups were conducted. Those subgroups were built on the basis of the students' performance and development level at the time of their school entrance (students with disadvantageous, good or very good learning preconditions in cognitive, language, literary language and mathematical areas). With the help of a propensity score matching, statistical twin groups between the treatment and control group were determined.

Age-matched and grade-matched comparisons between statistical twins were conducted with students who had to repeat a grade during the study period or who started to visit a DIC after their school beginning.

\subsection{Overview of the results}

Below, the results are summarized in order of the research questions.

- To which extend is a performance progress of students with individual cognitive preconditions noticeable in the treatment and control group and does the framework succeed to develop a 
performance-oriented elementary school despite using an inclusive schooling approach?

The study showed that the performance level of the treatment group in mathematics and reading is equivalent to the school performance of the control group as well as to regular performance standards throughout Germany. The students' results in writing are slightly below the overall average for both the treatment and control group.

Comparing the students" school performance with results from previous annual standard-based tests (VERA) of third-grade students, it turns out that there is a tendency towards a performance increase at elementary schools on Rügen: The performance level of the treatment group corresponds to the countrywide average - ,despite inclusion" - which has not always been the case in previous years.

Comparing the results between the statistical twin groups shows that the control group tends to perform better in mathematics and to some extend in writing. The advantages of the control group are statistically significant, yet the effect size is low (mathematics: $\mathrm{d}=0.31$; writing: $\mathrm{d}=0.28$ ). Disadvantageous performance results of statistical twins in the treatment group can most likely be attributed to regional and structural differences (see section Limits to the comparability of the study groups).

The overall inconspicuous results of the school performance in the treatment group as well as the comparatively advantageous performance of the study group in the VERA standard-based tests in 2013 speak against negative effects of school performance of students with different learning preconditions. This leads to the conclusion that there is no negative impact of the RIM framework on the school performance of students without additional or special educational needs.

- Which school setting is more benefiting for the development of students at risk of poor learning outcomes?

Evaluating the gathered data proves that students of the treatment group with poor learning outcomes in the subjects' mathematics, reading and writing already achieve the performance level of fourthgrade control group students after only three years at school. Under these conditions, they can further improve their reading and writing skills after another school year. Similar to international research, it can be said that additional educational support at mainstream schools has a positive impact on students with learning disabilities. The results reported are in line with other study results, which point to the positive effects of inclusive education on the academic performance [30, 31, 32, 33].
- Which school setting is more benefiting for the students' socio-emotional development and situation?

Results for the socio-emotional development and school experiences in both study groups and in parallel comparisons between both groups show that the treatment group clearly benefits from the inclusive school setting. These students show less inappropriate behavior and more prosocial behavior patterns. In our study, students at risk of difficulties in their socio-emotional development do not differ significantly when evaluating distinctive data about their socio-emotional status. Students with special needs in their socio-emotional development receive at least as sufficient support in the treatment group as in the control group.

- Which school setting is more benefiting for the language, school performance and socioemotional development particularly of students with language and speech disabilities?

There are no distinctive differences between students with specific language developmental difficulties in the treatment and control group in terms of their language and performance progress. Regarding their socio-emotional school experiences, it can be said that students from the control group, who went to elementary schools for students with language disabilities, show more joy in learning and have a better attitude towards school than students in the treatment group. The students' socio-emotional situation, however, is quite similar in both groups (overall problems, prosocial behavior, feeling of being accepted, willingness to increase effort, classroom atmosphere, self-concept of own capability at school and social integration). Students of the control group who have difficulties in their socio-emotional development but do not receive additional support are constantly disadvantageous in their socio-emotional situation.

- Do the different elementary school concepts of the treatment and control group lead to a different frequency and quality of additional educational support?

The percentage of students with officially diagnosed special educational needs is higher in the control group than in the treatment group. When considering all of the students with SEN (areas of learning, socio-emotional development and language) together, there is a need for special educational support, which is three times higher in the control group than in the treatment group $(12.3 \%$ vs. $3.8 \%$ ). Whereas the educational system for the control group leads to an extremely high rate of special educational support, the RIM concept reduces 
the need for special educational support significantly. Diagnosed learning disabilities, such as reading and writing or mathematics disabilities, a combination of disabilities in academic skills or special educational needs for learning, are in both groups within the expected area - in the treatment group even tendentially below this area. Results of a metaanalysis conducted by Burns, Appleton and Stehouwer [34] support our observation of a lower need for (special) educational support within a RTI framework.

Another point to be considered is that both school systems do not differ in the frequency of grade repetitions within the students' time at elementary school. With 5-6\% they are both below the expected results. Information from the European Commission from 2011 report a frequency of grade repetitions or other measures to extend the learning time (e.g. longterm classes) of $>15 \%$ at German elementary schools.

- Which effects regarding the emotional-social situation of the students can be achieved?

For the investigation of differential effects, groups of students were built: students without, with slight and with significant underachievement. The promotion of the emotional-social situation for students without and with slight underachievement has already been adequately achieved in the RIM. The students achieve average or above average values based on applicable standards. Findings for students with significant underachievement are less favorable. Here are the data on school motivational aspects (effort readiness, school attitude, learning pleasure and self-concept) only at T-value equivalents $\mathrm{T} \leq 35$. However, it should be noted that the school-related motivation is also low in the control group.

Contrary to the assumptions, in the comparison of the treatment group and the control group positive effects in the RIM are only shown for some of the examined factors (problem and prosocial behavior, feeling of being accepted, class climate, self-concept, self-perceived social integration). The benefits are primarily for students with slight underachievement. The effect is highest in the self-experienced class climate for students with significant underachievement $(d=0.69)$. This suggests that students with severe academic difficulties still feel class cohesion in RIM.

- To which extend do participating teachers accept new schooling approaches? Do teachers implement the core elements of the approach similarly?

Evaluating the answers from the teacher questionnaires leads to the conclusion that core elements of the RTI approach, such as the multi-level prevention system and data-based decision making are well accepted and implemented by special education teachers as well as elementary school teachers. The teachers' acceptance and implementation of the conceptual element to use research-based procedures and lesson materials in mathematics, reading and writing are high but nevertheless lower than for the multi-level prevention system and data-based decision making.

- To which extend are parents satisfied with the educational work according to the Rügen Inclusion Model?

We can conclude that parents of students in the treatment group are mostly satisfied with the school lessons, lesson materials and the educational support at school. More than $90 \%$ of all interviewed parents reported that their child feels comfortable and well accepted, that there is a positive classroom atmosphere, that their child likes to go to school and that students are also satisfied with the educational work. It is striking that clearly more parents of students in the treatment group state that they know about the learning situation of their students and how they are additionally supported.

\section{Limits to the comparability of the study groups}

Specific research results lead to the conclusion that a comparability of the regions is limited. Therefore, it is possible to underestimate some effects:

- An analysis of the annual standard-based tests (VERA) for third-grade students between 2009 and 2012 shows that the mathematics performance level on the Isle of Rügen were below the German-wide average in three of those four years. They were also below the achieved performance standard in Stralsund (control group). Moreover, the performance level in writing on Rügen and in Stralsund as well as in the rest of Mecklenburg-Western Pomerania was also below the overall average in three of the four analyzed years. Reading results from Rügen and Stralsund were mostly similar between 2009 and 2012.

- Further differences between the two regions lie in the parents' academic and professional level of education. Approximately one third of the parents of students in the control group achieved a high academic and professional degree. These are twice as many as parents of students in the treatment group. Parents of the treatment group students achieved more often a medium educational and professional degree than parents from the control group students. A significant 
difference of the parents' educational level is also supported by the fact that parents of students in the control group mostly have a higher income.

- With regards to school structural aspects, there are also differences noticeable between both regions: schools on the Isle of Rügen teach on average 136 students (between 35 and 243 students), whereas 198 students on average go to school in Stralsund (between 97 and 260 students). Schools on Rügen mostly comprise one to two parallel classes. Schools in Stralsund mostly comprise two to three parallel classes. Only one school has one class per grade level.

- The structure of lessons and educational support for the control group corresponds to the mainstream school system in MecklenburgWestern Pomerania. The Isle of Rügen as well as Stralsund follow the same school laws and decrees, which has led to a mostly similar educational supply in both regions. However, both regions differ distinctively in their extracurricular offers for additional educational support (e.g. therapies for dyscalculia or for reading and writing disabilities): In the control group, $16.7 \%$ of the students make use of these offers whereas in the treatment group only $5.6 \%$ do.

\section{Discussion}

If the aspect of school performance is taken as a primary indicator for judging a school system, both schooling concepts - the RIM framework and the traditional system - achieve similar results in the overall evaluation. Small advantages of the traditional school system in particular twin group comparisons can be traced back to school structural and socio-economic differences in the regions analyzed rather than the different schooling approaches themselves. The Rügen Inclusion Model, however, convinces with a considerably better learning progress after supporting students with disadvantageous learning preconditions.

Next to the school performance, the socioemotional development of students also plays a crucial role within a school system, which is why it should be included into the judgement as well. The acquired data clearly advocate the preventive and inclusive RIM. Students of the treatment group show better prosocial behavior and have more positive socio-emotional school experiences.

The results also support the RIM concept with regards to the rate of officially diagnosed special educational needs. After being taught according to the RIM, only one third compared to the students of the control group need special educational support in learning, their socio-emotional development and language. The frequency of grade repetitions and of partial learning disabilities are nearly similar in both school systems.

When looking at the overall results of specific areas of special educational needs, it becomes apparent that especially learning disabilities and also the socio-emotional development benefit from the inclusive framework. Both school systems have the same effectiveness for the students' speech and language development.

The RIM and the RTI approach do not only have a preventive effect, but they also fulfill the request of a joint school setting for students with (special) educational needs. Evaluating all results of the study leads to the conclusion that the RIM and RTI approach also help to provide available, accessible, acceptable and adaptable inclusive schooling for students with SEN and therefore fulfill requests of the UN Convention on the Rights of Persons with Disabilities. It is striking that these results have already been achieved after only four years of a proinclusion-reform. In summary, we can conclude that RTI can be regarded as an emerging and suitable alternative for an inclusive school system in Germany.

\section{Implications}

Even though the conclusions of the study are all in all positive, the acquired data also indicate that there are some elements of the RIM concept that should be further improved:

- First of all, teachers should be more included in the process of choosing scientifically approved lesson materials. Guidelines that support this process have already been developed $[35,36]$.

- Despite the efforts, students with significant underachievement tend to take on unfavorable social positions in their classes. The problems of this unsatisfactory social inclusion could not yet be solved sufficiently. The findings are consistent with other research results [3]. Even if one considers that it is unlikely that any inclusion-related concept will solve all emotional-social difficulties, the data point to an increased need for action. However, the data shows no evidence of negative effects of the RIM for students without academic underachievement. These students achieve noticeably high scores for the school selfconcept or the sense of being accepted (by the teacher) $(\mathrm{T}=61$ or $\mathrm{T}=59)$.

- Furthermore, it cannot be assumed that inclusive schooling structures will develop further on their own after a single implementation phase. Instead, the already implemented structures should be secured and further developed by quality-ensuring measures (for instance practical support, further teacher trainings, coaching for 
principals for an optimal support of the implementation).

- Finally, when implementing a preventive and inclusive school system, it is important to motivate especially the elementary school teachers for trying out new methods. There has been a quick and comprehensive reorganization of established school structures on the Isle of Rügen. It was possible with the help of intensive scientific support, but still there were many elementary school teachers, who could not be fully convinced by the new reforms. Therefore, it needs to be considered how fast and in which time frame such an inclusive school reform may be successfully implemented under these circumstances. Reports on experiences in the USA [37, 38] promote a gradual introduction of multi-level prevention systems, research-based practice and formative evaluations of lessons and long-term supporting measures. Thus, it is advisable to develop and test implementation strategies successively.

\section{Acknowledgements}

This research was funded by the Ministry of Education, Science and Culture MecklenburgWestern Pomerania/ Germany. We thank Laura Reckzeh for the lectureship of this manuscript.

\section{References}

[1] Bless, G. (2002) Zur Wirksamkeit der Integration. Forschungsüberblick, praktische Umsetzung einer integrativen Schulform, Untersuchungen zum Lernfortschritt, Haupt: Bern.

[2] Kocaj, A, Kuhl, P., Kroth, A. J., Pant, H. A. and Stanat P. (2014) 'Wo lernen Kinder mit sonderpädagogischem Förderbedarf besser? Ein Vergleich schulischer Kompetenzen zwischen Regel- und Förderschulen in der Primarstufe', Kölner Zeitschrift für Soziologie und Sozialpsychologie, 66 (2), pp. 165-191.

[3] DeVries, J. M., Voß, S. and Gebhardt, M. F. (submitted) 'Do learners with special education needs really feel included? The relationship between perception of inclusion and developmental strengths and difficulties ${ }^{6}$.

[4] Huber, C. and Wilbert, J. (2012) 'Soziale Ausgrenzung von Schülern mit sonderpädagogischem Förderbedarf und niedrigen Schulleistungen im gemeinsamen Unterricht", Empirische Sonderpädagogik, 4, pp. 147-156.

[5] Schwab, S., Gebhardt, M., Krammer, M. and Gasteiger-Klicpera, B. (2014) 'Linking self-rated social inclusion to social behaviour. An empirical study of students with and without special education needs in secondary schools', European Journal of Special Needs Education, 30 (1), pp. 1-14.
[6] Fuchs, D., Mock, D., Morgan, P. L. and Young, C. L. (2003) 'Responsiveness-to Intervention: Definitions, evidence, and implications for the learning disabilities construct $^{6}$, Learning Disabilities Research \& Practice, 18, pp. $157-171$.

[7] Hartmann, E. (2008) 'Konzeption und Diagnostik von schriftsprachlichen Lernstörungen im Responsiveness-toIntervention-Modell: eine kritische Würdigung', Vierteljahreszeitschrift für Heilpädagogik und ihre Nachbargebiete, 77, pp. 123-137.

[8] Walter, J. (2008) 'Adaptiver Unterricht erneut betrachtet: Über die Notwendigkeit systematischer formativer Evaluation von Lehr- und Lernprozessen und die daraus resultierende Diagnostik und Neudefinition von Lernstörungen nach dem RTI-Paradigma', Zeitschrift für Heilpädagogik, 59, pp. 202-215.

[9] Hinz, A. (2013) 'Inklusion - von der Unkenntnis zur Unkenntlichkeit!? - Kritische Anmerkungen zu einem Jahrzehnt Diskurs über schulische Inklusion in Deutschland', Zeitschrift für Inklusion, 1.

[10] Hughes, C. and Douglas, D. D. (2010) 'Field studies of RTI programs, revised"; http://www.rtinetwork.org/learn/research/field-studies-rtiprograms (27.02.2018).

[11] Blumenthal, Y., Kuhlmann, K. and Hartke, B. (2014) 'Diagnostik und Prävention von Lernschwierigkeiten im Aptitude Treatment Interaction- (ATI) und Response to Intervention- (RTI-)Ansatz' in Lernverlaufsdiagnostik, Hogrefe: Göttingen, Vol. 12, pp. 61-82.

[12] National Center on Response to Intervention (NCRTI) (2010) 'Essential Components of RTI - A Closer Look at Response to Intervention"; https://usm.maine.edu/sites/default/files/smart/rtiessentialc omponents_051310.pdf (27.02.2018).

[13] Berkeley, S., Bender, W.N., Peaster, L.G. and Saunders, L. (2009) 'Implementation of response to intervention: A snapshot of progress', Journal of Learning Disabilities, 42 (1), pp. 85-95.

[14] Caplan, G. (1964) Principles of preventive psychiatry, Basic Books: Oxford.

[15] Fuchs, D. and Fuchs, L.S. (2006) 'Introduction to Response To Intervention: What, Why, and How Valid Is It? ‘ Reading Research Quarterly, 41 (1), pp. 93-99.

[16] Fuchs, L. S. and Fuchs, D. (2007) 'Progress Monitoring in the Context of Responsiveness-toIntervention";

ttps://www.misd.net/mtss/ProgressMonitoring/ progress_monitoring_manual_2007.pdf (27.02.2018).

[17] Deno, S. L. (1985) 'Curriculum-based Measurement: The Emerging Alternative‘, Exceptional Children, 52, pp. 219-232.

[18] Deno, S. L. (2003) 'Developments in curriculumbased measurement", The Journal of Special Education, 37, pp. 184-192. 
[19] Hosp, M. K., Hosp, J. L. and Howell, K. W. (2007) The ABCs of CBM. A practical guide to curriculum-based measurement, Guilford Press: New York.

[20] Bundesministerium für Bildung (2016) 'Evidenzbasierte LRS-Förderung'; http://www.schulpsychologie.at/fileadmin/upload/lernen_1 eistung/Legasthenie/evidenzbas_LRS.pdf (27.02.2018).

[21] Grünke, M. (2006) 'Fördermethoden. Zur Effektivität von Fördermethoden bei Kindern und Jugendlichen mit Lernstörungen', Kindheit und Entwicklung, 15 (4), pp. 239-254.

[22] Barrish, H. H., Saunders, M. and Wolf, M. M. (1969) 'Good behavior game: Effects of individual contingencies for group consequences on disruptive behavior in a classroom', Journal of Applied Behavior Analysis, 2 (2), pp. 119-124.

[23] Hillenbrand, C. and Pütz, K. (2008) KlasseKinderSpiel. Spielerisch Verhaltensregeln lernen, Edition Körber-Stiftung: Hamburg.

[24] Lannie, A. L. and McCurdy, B. L. (2007) 'Preventing Disruptive Behavior in the Urban Classroom: Effects of the Good Behavior Game on Student and Teacher Behavior", Education and Treatment of Children, 30 (1), pp. 85-98.

[25] Hartke, B. and Vrban, R. (2010) Schwierige Schüler: 49 Handlungsmöglichkeiten bei Verhaltensauffälligkeiten, Persen: Buxtehude.

[26] Voß, S., Blumenthal, Y., Mahlau, K., Marten, K., Diehl, K., Sikora, S. and Hartke B. (2016) Der Responseto-Intervention-Ansatz in der Praxis: Evaluationsergebnisse zum Rügener Inklusionsmodell, Waxmann: Münster.

[27] Blumenthal, Y. and Voß, S. (2016) 'Effekte des Response to Intervention-Ansatzes auf die emotionale und soziale Situation von Grundschülern der vierten Jahrgangsstufe‘, Empirische Pädagogik, 30 (1), pp. 81-97.

[28] Goodman, R. (1997) 'The Strengths and Difficulties Questionnaire: A Research Note', Journal of Child Psychology and Psychiatry, 38 (5), pp. 581-586.

[29] Coie, J. D. and Dodge, K. A. (1988) 'Multiple Sources of Data on Social Behavior and Social Status in the School: A Cross-Age Comparison', Child Development, 59, pp. 815-829.

[30] Baker, E. T., Wang, M. C. and Walberg, H. T. (1994) 'The effects of inclusion on learning, Educational Leadership', 52 (4), pp. 33-35.

[31] Ruijs, N. M. and Peetsma, T T. D. (2009) 'Effects of inclusion on students with and without special educational needs reviewed', Educational Research Review, 4, pp. 6779.

[32] Markussen, E. (2004) 'Special education: Does it help? A study of special education in Norwegian upper secondary schools', European Journal of Special Needs Education, 19, pp. 33-48.

[33] Myklebust, J. O. (2006) 'Class placement and competence attainment among students with special educational needs', British Journal of Special Education, 33 , pp. 76-81.

[34] Burns, M. K., Appleton, J. J. and Stehouwer, J. D. (2005) 'Meta-analysis of response-to-intervention research: Examining field-based and research-implemented models', Journal of Psychoeducational Assessment, 23, pp. 381-394.

[35] Blumenthal, Y. and Mahlau, K. (2015) 'Effektiv fördern - Wie wähle ich aus? Ein Plädoyer für die Evidenzbasierte Praxis in der schulischen Sonderpädagogik', Zeitschrift für Heilpädagogik, 9, pp. 408-421.

[36] Voß, S., Sikora, S. and Hartke, B. (2015) 'Was heißt hier Evidenzbasiert?', Zeitschrift für Heilpädagogik, 66 (2), pp. 85-101.

[37] Batsche, G. M. (2006) 'Problem-Solving and Response to Intervention: Implications for State and District Policies and Practices'; http://www.casecec.org/powerpoints/rti/CASE\%20Dr.\%20 George\%20Batsche\%201-25-2006.ppt (27.02.2018).

[38] Fixsen, D. L., Naoom, S. F. Blase, K. A. and Wallace, F. (2007) 'Implementation: The Missing Link Between Research and Practice'; http://www.rtinetwork.org/ images/content/downloads/get\%20started/fixsen.pdf (27.02.2018) 